RUNNING HEAD: EXAMINING MENTAL HEALTH LITERACY IN UK COACHES

Examining mental health literacy, help seeking behaviours, distress, and wellbeing in UK coaches

Paul Gorczynski $^{1}$, Kass Gibson ${ }^{2}$, Nathan Clarke ${ }^{1}$, Tyrone Mensah ${ }^{1}$, and Rory Summers ${ }^{1}$

1 University of Portsmouth, Department of Sport and Exercise Science, Portsmouth, Hampshire, UK PO12ER

2 Marjon University, School of Sport, Health and Wellbeing, Plymonth, PL6 8BH

Corresponding Author: Paul Gorczynski, paul.gorczynski@port.ac.uk 


\title{
Examining mental health literacy, help seeking behaviours, distress, and wellbeing in UK coaches
}

\begin{abstract}
Although research has explored stress in coaches, little is known about their mental health literacy and how this is associated with their mental health. Their mental health literacy may have an impact on the wellbeing of their young players. This study examined levels of mental health literacy, help seeking behaviours, distress, and wellbeing as well as relationships amongst these variables in coaches in the UK. Coaches were recruited through social media and asked to fill out questionnaires. A total of 103 coaches $(n=65$ men, $n=37$ women, $n=$ one, an other gender) participated in the study. Coaches had an average age of 27.9 ( $\mathrm{SD}=10.6)$ years. Most selfidentified as heterosexual $(n=85,82.5 \%)$, had four or more years of experience $(n=46,44.7 \%)$, coached children $(n=77,75.5 \%)$, and coached at either the beginner $(n=30,29.1 \%)$ or amateur levels $(\mathrm{n}=66,64.1 \%)$. In total, $20(19.4 \%)$ coaches indicated a previous diagnosis of a mental disorder. A total of $51(49.5 \%)$ coaches indicated that, at the time of the completion of the survey, they exhibited symptoms of a mental disorder. Overall, the average mental health literacy score was 123.10 and lower than in previous studies. Mental health literacy was not significantly associated with help seeking behaviour, distress, or wellbeing. General help seeking behaviour was positively correlated with wellbeing. The results suggest that coach certification programmes could adopt strategies to help coaches improve their knowledge of mental health services and how such services may be accessed. These changes may improve the wellbeing of coaches and may benefit their athletes.
\end{abstract}

Keywords: mental health, mental health literacy, sport, coaches 


\section{EXAMINING MENTAL HEALTH LITERACY IN UK COACHES}

\section{Examining mental health literacy, help seeking behaviours, distress, and wellbeing in UK coaches}

\section{Introduction}

The mental health of athletes has been subject to much academic and media interest recently. The World Health Organization (WHO) defines mental health as: "a state of well-being in which every individual realizes his or her own potential, can cope with the normal stresses of life, can work productively and fruitfully, and is able to make a contribution to her or his community" (WHO, 2001, p1). Much like physical health, mental health is a resource. It allows people to function, deal with stress, perform meaningful work, and contribute to society. Mental disorders are forms of distress and dysfunction that can affect a person's cognitions, emotions, behaviours, and social relationships. Mental disorders must meet specific criteria for diagnosis and must be enduring, frequent, and severe (American Psychiatric Association, 2013). Research has demonstrated consistently that athletes, at all ages and levels of competition, are under pressure to perform well and deal with many stressors, which may result in poor mental health (Coyle et al., 2017; Gorczynski et al., 2017a; Gulliver et al., 2015; Gulliver, 2017; Rice et al., 2016).

Coaches play an important role in the development of their young players, both physically and mentally. Coaches have been identified as playing a vital role in being able to identify poor mental health in their youth athletes and encourage them to seek support (Coyle et al., 2017; Gorczynski, 2018; Gulliver et al., 2012). Coaches are in positions of importance in sports clubs and programmes, primarily responsible for the development and performance of their young players. Such responsibility carries tremendous psychological costs in the form of stress. Sociological literature has long shown not only the multiplicity of roles and 


\section{EXAMINING MENTAL HEALTH LITERACY IN UK COACHES}

responsibilities expected of coaches, including protecting youth athlete welfare (Borrie, 1998; Coakley, 1994), but also that coaches face many and varied stressors by virtue of their roles (Fletcher and Scott, 2010; Norris et al., 2017). Both performance-related and organizationalrelated stressors affect coaches (Thewell et al., 2008). Performance-related stressors for coaches relate to how they perform as coaches and the performance of the youth athletes they coach including stress related to training, competition preparation, competition performance, postcompetition, expectation management, and dealing with opponents and officials. Organizationalrelated stressors for coaches relate to the team, club, or organization they work for including: training environment, competition environment, team finances, team performance stability, youth athlete selection, travel schedules, safety of youth athletes and staff, administration and organizational issues, athletes, private life, social life, contractual issues, team atmosphere, team roles, and team communication.

The number of stressors coaches face has a direct impact on their mental health and, because of the transactional nature of stress (Lazarus and Folkman, 1987), the mental health of their youth athletes (Thelwell et al., 2016; Thelwell et al., 2017). The ability to identify and successfully cope with stressors benefits both coaches and the youth athletes they coach because how stressors and their consequences are perceived and addressed have significant implications for their own mental health and the mental health of their youth athletes (Thelwell et al., 2016; Thelwell et al., 2017). The more literate coaches are about mental health and identifying stressors, the more proactive they may be in addressing and reducing the stigma of poor mental health and supporting others to seek support. Specifically, strategies should focus on enhancing mental health literacy. 


\section{EXAMINING MENTAL HEALTH LITERACY IN UK COACHES}

Mental health literacy is defined by Jorm and colleagues (1997, p. 182) as "knowledge and beliefs about mental disorders which aid their recognition, management or prevention." Mental health literacy can be described as the knowledge individuals have about mental disorders, including their symptoms, causes, and forms of self-administered treatments; their attitudes toward poor mental health and help seeking behaviours, and their knowledge and intentions to seek help or support (Jorm, 2000; Wei et al., 2013).

Mental health literacy is a tool for personal and collective empowerment to acknowledge mental health inequities to improve health (Jorm, 2012; Gorczynski et al., 2019a; Gorczynski et al., 2019b). Importantly, mental health literacy is not merely the ability of individuals to detect symptoms of poor mental health, such as experiencing a low mood, but rather to drive individuals and their communities (e.g., sports teams and clubs) to collective action to acknowledge and address the determinants of mental health (Gorczynski et al., 2019a). As such, mental health literacy involves not only developing and using knowledge, but also changing attitudes, overcoming stigma, and providing and taking opportunities to get help. Therefore, mental health literacy is not simply 'information, education, and communication' (Nutbeam 2008, p. 439) to raise awareness in the expectation that people will therefore organise and attend appointments with mental health professionals. Mental health literacy encompasses creating collective and sustainable approaches for individuals and groups.

A number of studies have examined the use of mental health awareness training programmes, based on some tenets of mental health literacy, to improve mental health knowledge, attitudes, and help seeking behaviours amongst coaches (Bapat, Jorm, and Lawerence, 2009; Breslin, Haughey, Donnelly, Kearney, and Prentice, 2017a; Longshore and Sachs, 2015; Pierce, Liaw, Dobell and Anderson, 2010; Sebbens, Hassmen, Crisp and Wensley, 
2016). In their systematic review, Breslin and colleagues (2017b) showed that mental health awareness programmes resulted in reduced levels of negative affect (Longshore and Sachs, 2015), increased knowledge of mental health disorders (Bapat et al., 2009; Breslin et al., 2017a; Pierce et al., 2010; Sebbens et al., 2016), reduced levels of stigma (Bapat et al., 2009), increased confidence to help others who experience poor mental health (Breslin et al., 2017a; Pierce et al., 2010; Sebbens et al., 2016), and increased confidence to seek support from a mental health professional (Bapat et al., 2009). Breslin and colleagues (2017b) have pointed to numerous methodological limitations in the mental health awareness programmes evaluated to date, including limited use of valid and reliable psychometric instruments, a lack of control or comparison groups, non-theory based programming, and incomplete reporting of demographic information. Rigorous research has been recommended to address these methodological limitations, including addressing all major tenets of mental health literacy in any cross-sectional or prospective research (i.e., knowledge, attitudes, and intentions to seek support). Using valid and reliable methods to evaluate all major tenets of mental health literacy in relation to mental health outcomes would help identify which demographic and psychometric factors are most associated with mental health outcomes. This type of research would be helpful in laying the foundation for the creation of an evidence-based and theoretically sound mental health literacy intervention.

To date, one study has explored all major tenets of mental health literacy of coaches and athletic trainers using valid and reliable instruments (Sullivan et al., 2019). Cross-sectional research by Sullivan and colleagues (2019) in Canada showed that women had higher levels of mental health literacy than men and that significant negative relationships existed between age and mental health literacy and between years of coaching experience and mental health literacy. 
Findings suggest that younger coaches may be more literate in mental health than older more experienced coaches, perhaps being more aware of symptoms of mental disorders, having more positive attitudes toward poor mental health and treatment, and having more knowledge of how to go about seeking help. The research conducted by Sullivan and colleagues (2019) pointed to the need for mental health literacy strategies to specifically target men to become more informed about symptoms of mental disorders, have more positive attitudes toward poor mental health and help seeking, and be better informed about help seeking for poor mental health. Given the study was conducted in Canada using a small sample size of coaches, Sullivan and colleagues (2019) caution against generalizing the findings to any other country and, as suggested by O'Connor and Casey (2015), encourage replication in other settings. As such, the purpose of the current study was to (i) examine the mental health literacy, help seeking behaviours, distress, and wellbeing of sport coaches in the United Kingdom (UK); and (ii) evaluate relationships between these mental health variables.

\section{Method}

\section{Setting and sample}

This online survey study took place in the spring of 2018 and followed the same design as used by Gorczynski and colleagues (2017b) and O’Connor and Casey (2015). Inclusion criteria included individuals who were over the age of 18 years, a coach of any sport, and lived in the UK. After ethical approval, advertisements were posted on social media to recruit individuals who met inclusion criteria. If participants met inclusion criteria and provided informed consent, they then clicked on the link provided in the advertisement and filled out the required 
questionnaires online administered through Google Forms. No time limits were imposed on the participants to complete the survey.

\section{Materials}

\section{Demographic and coaching data}

Participants were asked to provide information on age, gender, ethnicity, sexuality, mental health information, years of coaching experience, coaching qualification (i.e., have obtained a UK Coaching Certificate), coaching level (i.e., Beginner, Amateur, Professional/Elite), and the predominant sport the participant coached.

\section{Mental Health Literacy Scale (MHLS)}

The MHLS is a 35 item measure of mental health literacy (O'Connor and Casey, 2015). The scale assesses disorder recognition, knowledge of help seeking information, knowledge of risk factors and causes, knowledge of professional treatments, and attitudes toward promoting mental health and help-seeking behaviours. The MHLS has a range of 35 to 160, with greater scores indicating greater level of mental health literacy. The MHLS has been found to have good internal consistency with a Cronbach's alpha of .873 and test-retest reliability $(r=.797, p<0.001)$ (O’Connor and Casey, 2015). For this study, questions nine and ten were changed to reflect the UK context, where "Australia" was swapped with "UK." The current study showed good internal consistency of $\alpha=.868$. 


\section{EXAMINING MENTAL HEALTH LITERACY IN UK COACHES}

\section{General Help-Seeking Questionnaire (GHSQ)}

One question from the GHSQ was used to assess intentions to seek help for poor mental health from specific individuals (Wilson et al., 2007). Participants were asked: "If you were having a personal or emotional problem, how likely is it that you would seek help from the following people?" On a scale of one (extremely unlikely) to seven (extremely likely), participants were asked about their level of intention to seek help from an intimate partner, a friend, a parent, a family member, a mental health care professional, a phone helpline, a doctor, a religious leader, or anyone else. Higher scores reflected a greater intention to seek help from a specific individual with respect to poor mental health. Previous research has shown the GHSQ to have good testretest reliability $(\mathrm{r}=.92)$ (Wilson et al., 2007), and be highly correlated with seeking counselling $\left(\mathrm{r}_{\mathrm{s}}=.17, \mathrm{p}<0.05\right)$ (Wilson et al., 2007).

\section{Kessler Psychological Distress Scale 10 (K10)}

The K10 is a 10 item measure of psychological distress (Kessler et al., 2002). On a scale of one (none of the time) to five (all of the time), participants were asked about their level of agreement to different statements, where higher scores indicated higher levels of distress. The K10 has a range of 10 to 50, with scores under 20 indicating an individual is likely to be well and not in distress. The K10 is accurate and reliable as it has been shown to have good discriminant validity (Australian Bureau of Statistics, 2007) and good reliability (Kessler et al., 2002). In the current study, the K10 indicated excellent internal consistency with a Cronbach's alpha of .922. 


\section{Warwick-Edinburgh Mental Well-Being Scale (WEMWBS)}

The WEMWBS is a 14 item measure of mental well-being (Tennant et al., 2007). On a scale of one (none of the time) to five (all of the time), participants were asked about how often they felt aspects of positive mental health, where higher scores indicated higher levels of mental wellbeing. The WEMWBS has a range of 14 to 70 . The WEMWBS has been shown to have good internal consistency (Cronbach's alpha of .89) and good test-retest reliability (r=.83) (Tennant et al., 2007). In the current study, the WEMWBS indicated excellent internal consistency with a Cronbach's alpha of .936.

\section{Data analysis}

Given the non-parametric nature of the data, differences in mental health variables for gender, ethnicity, sexuality, coaching experience, and coaching certification were examined through Kruskal-Wallis H and Mann-Whitney U tests. Relationships amongst variables were examined through Spearman correlations. An alpha level of .05 was used for all analyses.

Results

\section{Demographic and coaching data}

A total of 103 individuals took part in the study. The sample consisted of 65 men, 37 women, and one individual who identified as another gender. Individuals were between the ages of 19 and 70 years, with a mean age of 27.87 years $(\mathrm{SD}=10.58$ years $)$. The majority of individuals identified as heterosexual $(n=85,82.5 \%)$ and white $(n=71,68.9 \%)$. Most individuals coached children ( $n=77,74.8 \%)$. Most commonly, individuals coached rugby $(n=29,28.2 \%)$ or football $(n=16,15.5 \%)$, had over four or more years of coaching experience $(n=46,44.7 \%)$, and coached 


\section{EXAMINING MENTAL HEALTH LITERACY IN UK COACHES}

at either the beginner $(n=30,29.1 \%)$ or amateur $(n=66,64.1 \%)$ levels. A total of 80 individuals (77.7\%) had a UK Coaching Certificate. With respect to a previous diagnosis of a mental disorder, 20 indicated yes (19.4\%). Complete demographic data can be seen in Table 1 and coaching data can be seen in Table 2 .

\section{MHLS}

The average MHLS score was $123.10(\mathrm{SD}=12.95$, range=80.00-150.00, 95\% $\mathrm{CI}=120.57-125.63)$. There was no significant difference in MHLS scores between those who did and did not have a previous diagnosis of a mental disorder $(\chi 2(2)=5.734, \mathrm{p}=0.057)$. Women had a significantly higher MHLS score $(M=126.84, S D=11.20)$ than men $(M=120.75, S D=13.42)(\chi 2(2)=7.016, p$ $=0.030 ; \mathrm{U}=870, \mathrm{p}=.021)$. There were no statistical differences in MHLS between ethnicities $(\chi 2(4)=4.545, p=0.337)$ and sexualities $(\chi 2(2)=.616, p=0.735)$. Individuals with one year of coaching experience $(\mathrm{M}=130.53, \mathrm{SD}=16.73)$ had significantly higher levels of MHLS scores than individuals with two $(\mathrm{M}=122.81, \mathrm{SD}=11.73)$, three $(\mathrm{M}=119.53, \mathrm{SD}=13.88)$, and four or more years $(M=121.96, S D=10.72)$ of coaching experience $(\chi 2(3)=10.155, \mathrm{p}=0.017)$. There was no statistical difference in MHLS scores between individuals who coaches children or adults $(\chi 2(1)=.345, \mathrm{p}=0.557)$ and who had or did not have a UK Coaching Certificate $(\chi 2(1)=.091, \mathrm{p}$ $=0.763)$.

\section{GHSQ}

The average GHSQ score was $35.31(\mathrm{SD}=9.75$, range=13.00-62.00, 95\% $\mathrm{CI}=33.39-37.21)$. Individuals indicated they were most willing to seek support from intimate partners $(M=5.03$, $\mathrm{SD}=1.718)$ and friends $(\mathrm{M}=4.77, \mathrm{SD}=1.821)$ and least likely to seek support from religious 


\section{EXAMINING MENTAL HEALTH LITERACY IN UK COACHES}

leaders $(\mathrm{M}=2.05, \mathrm{SD}=1.671)$ and through phone help lines $(\mathrm{M}=3.06, \mathrm{SD}=1.857)$. There was no significant difference in GHSQ scores between those who did and did not have a previous diagnosis of a mental disorder $(\chi 2(2)=3.410, \mathrm{p}=.182)$. There were no statistical differences in GHSQ scores between genders $(\chi 2(2)=2.061, \mathrm{p}=0.357)$ or ethnicities $(\chi 2(4)=3.516, \mathrm{p}=$ $0.475)$. There were statistical differences in GHSQ scores between sexualities $(\chi 2(2)=7.976, p=$ 0.019). Individuals who identified as heterosexual $(M=35.00, S D=9.47)$ had statistically lower GHSQ scores than those individuals who identified as gay or lesbian $(\mathrm{M}=41.64, \mathrm{SD}=8.53)$ $(\mathrm{U}=263.5, \mathrm{p}=.019)$. Individuals who identified as bisexual $(\mathrm{M}=29.00, \mathrm{SD}=10.86)$ had statistically lower GHSQ scores than individuals who identified as gay or lesbian $(U=15.5, p=.035)$. There were no statistical differences between years of coaching experience $(\chi 2(3)=3.852, p=.278)$, whether they coached children or adults $(\chi 2(1)=1.932, \mathrm{p}=.165)$, or whether individuals had or did not have a UK Coaching Certificate $(\chi 2(3)=2.705, \mathrm{p}=0.100)$.

\section{K10}

The average $\mathrm{K} 10$ score was $21.15(\mathrm{SD}=7.63$, range $=10.00-45.00,95 \% \mathrm{CI}=19.66-22.64)$. A total of 51 individuals (49.5\%) indicated they may have at least a mild mental disorder (K10 $\geq 20)$. There was no significant difference in K10 scores between those who did and did not have a previous diagnosis of a mental disorder $(\chi 2(2)=5.194, p=0.074)$. There were no statistical differences in K10 scores between genders $(\chi 2(2)=5.118, \mathrm{p}=0.077)$ and ethnicities $\left(\chi^{2}(4)=\right.$ $3.482, \mathrm{p}=0.481)$. There were statistical differences in $\mathrm{K} 10$ scores between sexualities $(\chi 2(2)=$ 15.692, $\mathrm{p}=0.000$ ). Individuals who identified as heterosexual had significantly lower K10 scores $(M=19.49, \mathrm{SD}=6.03)$ than those who identified as bisexual $(\mathrm{M}=31.00, \mathrm{SD}=6.43)$ $(\mathrm{U}=62.00, \mathrm{p}=.001)$ and gay and lesbian $(\mathrm{M}=27.64, \mathrm{SD}=11.18)(\mathrm{U}=269.5, \mathrm{p}=.023)$. There were no 


\section{EXAMINING MENTAL HEALTH LITERACY IN UK COACHES}

statistical differences in K10 scores between years of coaching experience $(\chi 2(3)=4.544, \mathrm{p}=$ $0.208)$ and whether individuals had or did not have a UK Coaching Certificate $(\chi 2(1)=.592, \mathrm{p}=$ 0.442). Individuals who coached adults had significantly higher levels of distress $(M=23.64$, $\mathrm{SD}=8.25)$ than those who coached children $(\mathrm{M}=20.03, \mathrm{SD}=6.77)(\chi 2(1)=3.871, \mathrm{p}=.049)$.

\section{WEMWBS}

The average WEMWBS score was $49.17(\mathrm{SD}=10.77$, range=14-70, 95\% $\mathrm{CI}=47.06-51.27)$. There was a significant difference in WEMWBS scores between those who did and did not have a previous diagnosis of a mental disorder $(\chi 2(2)=9.258, \mathrm{p}=0.010)$, where individuals with a previous diagnosis of a mental disorder had significantly lower wellbeing $(\mathrm{M}=43.75, \mathrm{SD}=8.59)$ than those with no previous diagnosis $(\mathrm{M}=50.40, \mathrm{SD}=11.00)(\mathrm{U}=472.00, \mathrm{p}=.004)$. There were no statistical differences in WEMWBS scores between genders $(\chi 2(2)=1.459, \mathrm{p}=0.482)$ or ethnicities $(\chi 2(4)=5.544, p=0.236)$. There was a statistical difference in WEMWBS scores between sexualities $(\chi 2(2)=6.312, p=0.043)$. Individuals who identified as heterosexual had significantly higher scores of WEMWBS scores $(M=50.16, S D=10.67)$ than those who identified as bisexual $(\mathrm{M}=40.29, \mathrm{SD}=10.05)(\mathrm{U}=131.50, \mathrm{p}=.014)$. There were no statistical differences in WEMWBS scores between those who identified as heterosexual and gay or lesbian $(U=389.50$, $p=.369)$ and between those who identified as bisexual and gay or lesbian $(U=26.50, p=.285)$. There were no statistical differences in WEMWBS scores between years of coaching experience $(\chi 2(3)=1.426, p=0.700)$, whether they coached children or adults $(\chi 2(1)=.403, p=.526)$, or whether individuals had or did not have a UK Coaching Certificate $(\chi 2(1)=.476, p=0.490)$. 


\section{Comparing mental health literacy with help seeking behaviours, distress, and wellbeing}

Age in years was not significantly correlated with MHLS, GHSQ, K10, or WEMWBS ( $\mathrm{p}>.05$ ).

The MHLS score was not significantly correlated with GHSQ, K10, or WEMWBS ( $>$.05). The GHSQ score was significantly positively correlated with WEMWBS $(\mathrm{r}(203)=.336 \mathrm{p}=.001)$, indicating that those with higher intentions to seek support for mental health problems also had higher levels of mental wellbeing. The K10 total score was significantly negatively correlated with WEMWBS $(r(103)=-.549 \mathrm{p}=.000)$, indicating that those with higher levels of distress had lower levels of mental wellbeing. 


\section{EXAMINING MENTAL HEALTH LITERACY IN UK COACHES}

\section{Discussion}

The purpose of this study was to examine the mental health literacy, help seeking behaviours, distress, and wellbeing of sport coaches in the UK. A further purpose of this study was to examine relationships between these mental health variables. Overall, the level of mental health literacy was lower than seen in previous research that has examined the mental health literacy of Canadian coaches and athletic trainers who completed the MHLS (M=131.48; Sullivan et al., 2019). Additionally, mental health literacy in the current study was lower than mental health literacy scores seen in Australian university students (M=127.4; O'Connor and Casey, 2015), Australian community samples (M=128.00; White and Casey, 2016), and Australian health care professionals (M=145.5; O'Connor and Casey, 2015). When the mental health literacy results of the current study were compared to those of university students in the UK, results were similar (M=122.88; Gorczynski, et al., 2017b). As pointed out by Kutcher and colleagues (2016), mental health literacy is context specific. It is a construct that measures levels of knowledge of mental health, and attitudes toward poor mental health and mental health help services. It also measures how integrated this knowledge and these attitudes are in existing social and organizational structures. The results of this study may illustrate a cultural difference between the UK, Canada, and Australia regarding how poor mental health is viewed, understood, and acted upon. Further research with the MHLS is necessary to determine whether such differences in mean scores are in fact held consistently across countries, different groups of individuals, and are clinically significant. Practically, individuals running mental health literacy programmes need to be mindful of cultural differences with respect to knowledge and attitudes toward poor mental health. Programmes should be progressive with greater and more in-depth knowledge introduced at successive stages of coaching certification. 


\section{EXAMINING MENTAL HEALTH LITERACY IN UK COACHES}

A further finding of this study was that mental health literacy was higher in women than men. This finding supports the results of Sullivan and colleagues (2019) and may reinforce the need for specific attention paid to the knowledge, attitudes, and help seeking behaviours of men. Seidler and colleagues (2017) have previously advocated for diverse and gender-sensitive models and styles of mental health promotion to help men better understand and address poor mental health. Seidler and colleagues (2017) propose mental health support campaigns that promote diversity in men and present mentally healthy masculinities. Such research and eventual campaigns will need to recognize the needs of men of various sexualities and ethnicities. In the present study, although there were no differences in the mean mental health literacy scores amongst individuals of different sexualities, significant differences existed in levels of distress, those who identified as heterosexual had lower scores of distress than individuals who were bisexual or gay. Such findings reinforce the need to be mindful of how to address discrimination and harassment based on sexuality in sport (DeFoor et al., 2018; Gorczynski and Brittain, 2016). Similarly with regards to ethnicity, although no significant differences between races were found for mean scores for mental health literacy or distress, previous research has shown that ethnic minority status is a determinant of poor mental health (Cokley et al., 2011). Further research is needed on how such mental health literacy campaigns might be constructed, implemented, and evaluated in a sports context. Specifically, such campaigns need to be mindful as to how demographic factors that influence poor mental health are covered in any future curriculum.

In the current study, a total of 51 individuals ( 30 men, 20 women, and one person who identified by an other gender) indicated a score that may be symptomatic of at least a mild mental disorder. Overall, no significant differences were found with respect to distress between men and women. This is a departure from previous research that has illustrated significant 


\section{EXAMINING MENTAL HEALTH LITERACY IN UK COACHES}

differences in poor mental health between genders in sport contexts (Gorczynski et al., 2107a). This result may be due to a smaller sample of women, in comparison to men, who participated in

the study. Future research and interventions need to recruit robust samples of women and should continue to take into consideration the mental health needs of women and how mental health literacy campaigns can be shaped to meet the needs of diverse audiences.

Findings from this study show that age was not significantly associated with mental health literacy, or any other mental health variable. This finding is in contrast to the results found by Sullivan and colleagues (2019), Farrer and colleagues (2008), and White and Casey (2016), which have all shown that younger individuals were more literate in mental health than older individuals. However, findings in the current study are in line with Sullivan and colleagues (2019) which showed that individuals with only one year of coaching experience had significantly higher levels of mental health literacy than those with two or more years of coaching experience. This may suggest that new coaches may simply be more aware of poor mental health and may be less impacted by cultural aspects of sport (i.e., the development of bad habits), the impact of which may accrue over time which may result in turning a blind eye to either the causes of poor mental health or the symptoms of poor mental health. Furthermore, no significant differences were found in mental health literacy between those individuals who had or did not have a UK Coaching Certificate. Rigorous prospective studies are needed to explore this relationship further, specifically to determine if pedagogical changes to UK Coaching with a focus on continued training in mental health literacy may have a positive impact on symptom knowledge, attitudes toward poor mental health, and help seeking behaviours as well as helping others to seek support when necessary. Research by Hegarty and colleagues (2018) has shown that coaches may have good knowledge of depression, but lack awareness of the symptoms in 


\section{EXAMINING MENTAL HEALTH LITERACY IN UK COACHES}

their athletes and others. Hegarty and colleagues (2018) suggested that coaches were open and interested in formal mental health education. Research by Sebbens and colleagues (2016) has shown that a 4-hour mental health literacy intervention can have a lasting effect on coaches and support staff, indicating both increased knowledge of symptoms of common mental illnesses and confidence to refer someone to a mental health professional six to eight weeks after the intervention.

Findings from this study suggest who coaches would prefer to seek support from for poor mental health. Coaches would be most likely to seek help from their partners, friends, parents, before approaching mental health professionals and their GPs. These findings may be a reflection of public perceptions of mental health service provisions in the UK and how difficult they are to access. Research that has investigated the impact of austerity policies introduced in the UK in the early 2010s has shown a decrease in funding for mental health services in the National Health Service (NHS) budget (Cummins, 2017; LSE, 2012). Currently, mental illness represents 23\% of the total disease burden in the UK, yet receives 13\% of the NHS budget (LSE 2012). Specifically, the LSE report (2012) stated that financial pressures and limited service availability have made mental health support services difficult to access, thereby presenting people a real barrier to obtaining help. In addition to limited service availability and access, other challenges may have impacted why coaches were not willing to seek support from mental health professionals. Given the limited mental health literacy illustrated in this study, coaches may have not known about how to access the services of mental health professionals or have confidence in their opinion. Research by Gulliver, Griffiths, and Christensen (2012) has shown that multiple barriers, including a lack of knowledge, negative attitudes about professional services, and practical considerations like a lack of time and money, all impact why athletes do not access 


\section{EXAMINING MENTAL HEALTH LITERACY IN UK COACHES}

professional mental health services. Although previous research has shown significant associations between mental health literacy and general help seeking intentions to address poor mental health (Gorczynski et al., 2017b; Kelly et al., 2007), no significant relationships were found in this study. This finding further reinforces the need to better understand the unique context of coaches, their knowledge and attitudes toward poor mental health and treatment, and how it influences barriers to seeking help. Ultimately, if coaches are more willing to seek support from mental health professionals, they may also be more willing to refer their youth athletes to such services. From a practical perspective, individuals running mental health literacy programmes need to convey to coaches clear pathways of help seeking behaviour, specifically identifying who to turn to and how to go about obtaining support. This would require mental health literacy programmes to have up-to-date information on local services and specific information coaches may wish to convey about their mental health to their service providers.

A correlational analysis of mental health literacy, distress, and wellbeing in the current study showed there were no significant relationships between these variable, results that are in line with previous research by O'Connor and Casey (2015). These results may illustrate that knowing about poor mental health, symptoms of mental disorders, self-care practices, and resources, in addition to maintaining a positive attitude about poor mental health and help seeking, is not related to poor mental health. To address the poor mental health of coaches, the culture of sport needs to change where performance-related and organizational-related stressors that affect coaches need to be addressed, in addition to implementing any literacy strategies (Thewell et al., 2008). Mental health literacy training can play a part in raising awareness of the sources of poor mental health amongst coaches as well as bringing coaches together to find and promote strategies to address the sources of poor mental health. Furthermore, mental health 


\section{EXAMINING MENTAL HEALTH LITERACY IN UK COACHES}

literacy was not significantly associated with help seeking behaviours. This is a departure from the work of Gorczynski and colleagues (2017b) and O'Connor and Casey (2015), who found significant relationships between these variables, suggesting that those who know more about mental health are more likely to have more positive attitudes toward poor mental health and seek support professionally. Given a positive significant relationship was found between GHSQ and wellbeing in the current study, helping individuals understand where and how to access professional mental health support may have an impact on the overall wellbeing coaches and youth athletes. Further research is needed to explore this relationship and better understand how intentions to seek support are influenced. Here researchers may wish to explore specific factors that influence intentions, such as behavioural beliefs, normative beliefs, and control beliefs related to help seeking behaviours. Recent research by Breslin and colleagues (2019) showed that the Theory of Reasoned Action may be used to better understand demographic factors that influence intentions.

This study has a number of strengths and limitations that should be mentioned. First, this is the first study in the UK to examine mental health literacy in coaches. Results from this study may provide a baseline to assess future cross-sectional and intervention studies. Second, detailed demographic data were collected in this study, including information on ethnicity and sexuality. Such detailed data should help with the design of future studies and interventions. With regards to limitations, first, caution must be taken when generalizing results from this cross-sectional study. As such, only relationships may be assumed from these results and not any form of causation. Second, there was an over representation of men in this study. Research in the UK has found that amongst active coaches (i.e., those who have been coaches within the last 12 months), $54 \%$ of individuals identify as men and $46 \%$ of individual identify as women (UK Coaching, 
2018). Efforts must be made in future research to obtain more representative samples. Third, this study relied on results obtained from self-report measurements. Despite illustrating good reliability for all measures, there is the possibility that social desirability may have played a role in how individuals answered questions. Future studies that wish to investigate relationships between mental health literacy and poor mental health may wish to seek alternative manners of obtaining mental health diagnostic data. Fourth, no time limits were imposed on the participants to complete their surveys and time to complete the survey was not captured. This means that participants could have taken multiple days to complete the survey where they may have accessed sources of information on poor mental health. Researchers in future studies may wish to capture length of time to complete the survey to examine if any relationships exist between time to complete the survey and mental health literacy. Researchers may also wish to impose reasonable time limits to complete the survey. Overall, much remains to be studied in better understanding the poor mental health of coaches and how mental health literacy strategies can help not only this population but also the youth athletes they work with. 
References

American Psychiatric Association (2013) Diagnostic and statistical manual of mental disorders (5th edition). Arlington, VA: American Psychiatric Publishing.

Bapat S, Jorm A, Lawrence K (2009) Evaluation of a mental health literacy training program for junior sporting clubs. Australasian Psychiatry 17:475-479.

Borrie A (1998) Coaching: Art or science? Insight 1(1): 5.

Breslin G, Haughey TJ, Donnelly P, and Prentice G (2017a) Promoting mental health awareness in sport clubs. Journal of Public Mental Health 16(2):55-62.

Breslin G, Shannon S, Haughey T, Donnelly P, and Leavey G (2017b) A systematic review of interventions to increase awareness of mental health and well-being in athletes, coaches and officials. Systematic Reviews, 6(1), 177.

Breslin G, Shannon S, Ferguson K, Devlin S, Haughey T, and Prentice G (2019) Predicting Athlete Mental Health Stigma Using the Theory of Reasoned Action Framework. Journal of Clinical Sport Psychology 13(1):103-115. 
Coakley JJ (1994) Sport and society: Issues and controversies (5 ${ }^{\text {th }}$ edition). St Louise: CV Mosby.

Cokley K, Hall-Clark B, and Hicks D (2011) Ethnic minority-majority status and mental health: The mediating role of perceived discrimination. Journal of Mental Health Counseling 33(3): $243-263$.

Coyle M, Gorczynski P, and Gibson K (2017) "You have to be mental to jump off a board any way": Elite divers' conceptualizations and perceptions of mental health. Psychology of Sport and Exercise 29: 10-18.

Cummins I (2018) The Impact of Austerity on Mental Health Service Provision: A UK Perspective. International Journal of Environmental Research and Public Health 15(6). doi: 10.3390/ijerph15061145

DeFoor MT, Stepleman LM, and Mann PC (2018) Improving Wellness for LGB Collegiate Student-Athletes Through Sports Medicine: A Narrative Review. Sports Medicine-Open 4(48). doi: 10.1186/s40798-018-0163-y

Farrer L, Leach L, Griffiths KM, Christensen H, and Jorm AF (2008) Age differences in mental health literacy. BMC Public Health 8. doi:10.1186/1471-2458-8-125 
Fletcher D and Scott M (2010) Psychological stress in sports coaches: A review of concepts, research, and practice. Journal of Sport Science 28(2): 127-137.

Gorczynski P (2018) Developing mental health literacy in coaches. In: Thelwell R and Dicks M (eds.) Professional Advances in Sports Coaching: Research and Practice. Abingdon-on-Thames, UK: Routledge.

Gorczynski P and Brittain D (2016) Call to action: The need for an LGBT focused physical activity research strategy. American Journal of Preventative Medicine 51(4): 527-530.

Gorczynski P, Coyle M, and Gibson K (2017a) Depressive symptoms in high-performance athletes and non-athletes: a comparative meta-analysis. British Journal of Sport Medicine 51(18): 1349-1354.

Gorczynski P, Gibson K, Thelwell R, Papathomas A, Harwood C, and Kinnafick F (2019a) The BASES Expert Statement on Mental Health Literacy in Elite Sport. The Sport and Exercise Scientist 59: 6-7.

Gorczynski P, Rathod S, and Gibson K (2019b). Using health equity to guide future physical activity research involving people living with serious mental illness. In: Bird SR (ed) Research Methods in Physical Activity and Health. New York, NY: Routledge, pp. 317-323.

Gorczynski P, Sims-Schouten W, Wilson C, and Hill D (2017b) Examining mental health 
literacy in UK university students. Journal of Mental Health Training, Education and Practice 12(2): 111-120.

Gulliver A, Griffiths KM, Christensen H (2010) Perceived barriers and facilitators to mental health help-seeking in young people: a systematic review. BMC Psychiatry 10:113. doi: $10.1186 / 1471-244 X-10-113$

Gulliver A, Griffiths KM, and Christensen H (2012) Barriers and facilitators to mental health help-seeking for young elite athletes: A qualitative study. BMC Psychiatry 12:157. doi: $10.1186 / 1471-244 X-12-157$

Gulliver A, Griffiths KM, Mackinnon A, Batterham PJ, and Stanimirovic R (2015) The mental health of Australian elite athletes. Journal of Science and Medicine in Sport 18(3): 255-261.

Gulliver A (2017) Commentary: Mental Health in Sport (MHS): Improving the Early Intervention Knowledge and Confidence of Elite Sport Staff. Frontiers in Psychology 8:1209. doi: 10.3389/fpsyg.2017.01209

Hegarty EM, Weight E, and Register-Mihalik JK (2018) Who is coaching the coach? Knowledge of depression and attitudes toward continuing education in coaches. BMJ open sport \& exercise medicine 4(1): e000339. 
Jorm AF, Korten AE, Jacomb PA, Christensen H, Rodgers B, and Pollitt P (1997) "Mental health literacy": a survey of the public's ability to recognise mental disorders and their beliefs about the effectiveness of treatment. Medical Journal of Australia 166(4):182-186.

Jorm AF (2000) Mental health literacy. Public knowledge and beliefs about mental disorders. The British Journal of Psychiatry 177: 396-401.

Jorm AF (2012) Mental health literacy: Empowering the community to take action for better mental health. The American Psychologist 67(3): 231-243.

Kessler RC, Andrews G, Colpe LJ, Hiripi E, Mroczek DK, Normand SLT, Walters EE and Zaslavsky AM (2002) Short screening scales to monitor population prevalence's and trends in non-specific psychological distress. Psychological Medicine 32(6): 959-976.

Kelly CM, Jorm AF, and Wright A (2007). Improving mental health literacy as a strategy to facilitate early intervention for mental disorders. The Medical Journal of Australia 187(7 Suppl): S26-S30.

Kutcher S, Wei Y, and Coniglio C (2016) Mental health literacy: Past, present, and future. The Canadian Journal of Psychiatry 61(3):154-158.

Lazarus RS and Folkman S (1987) Transactional theory and research on emotions and coping. European Journal of Personality 1(3): 141-169. 
London School of Economics (2012) How Mental Illness Loses Out in the NHS. Available online: $\underline{\text { http://cep.lse.ac.uk/pubs/download/special/cepsp26.pdf }}$

Longshore K, Sachs M (2015) Mindfulness training for coaches: a mixed-method exploratory study. Journal of Clinical Sport Psychology 9:116-137.

Norris LA, Didymus FF, and Kaiseler M (2017) Stressors, coping, and well-being among sports coaches: A systematic review. Psychology of Sport and Exercise 33: 93-112.

Nutbeam D (2008) The evolving concept of health literacy. Social Science \& Medicine 67(12): 2072-2080.

O’Connor M and Casey L (2015) The Mental Health Literacy Scale (MHLS): A new scale-based measure of mental health literacy. Psychiatry Research 229(1-2): 511-516.

Pierce D, Liaw S, Dobell J, and Anderson R (2010) Australian rural football club leaders as mental health advocates: an investigation of the impact of the coach the coach project. International Journal of Mental Health Systems 4:10.

Rice SM, Purcell R, De Silva S, Mawren D, McGorry PD, and Parker AG (2016) The mental health of elite athletes: A narrative systematic review. Sports Medicine (Auckland, N.Z.) 46(9):1333-1353. 
Sebbens J, Hassmen P, Crisp D, and Wensley K (2016) Mental Health in Sport (MHS): Improving the Early Intervention Knowledge and Confidence of Elite Sport Staff. Frontiers in Psychology 7:911. doi: 10.3389/fpsyg.2016.00911

Seidler ZE, Rice SM, Olieffe J, Fogarty AS, and Dhillon HM (2018) Men in and out of treatment for depression: Strategies for improved engagement. Australian Psychologist 53(5): 405-415.

Storch EA, Storch JB, Killiany EM, and Roberti JW (2005) Self-reported psychopathology in athletes: A comparison of intercollegiate student-athletes and non-athletes. Journal of Sport Behavior 28(1): 86-98.

Sullivan P, Murphy J, Blacker M (2019) The Level of Mental Health Literacy Among Athletic Staff in Intercollegiate Sport. Journal of Clinical Sport Psychology 13(3): 440-450.

Tennant R, Hiller L, Fishwick R, Platt P, Joseph S, Weich S, Parkinson J, Secker J, and Stewart-Brown S (2007) The Warwick-Edinburgh mental well-being scale (WEMWBS): Development and UK validation. Health and Quality of Life Outcome 5(63). doi: 10.1186/14777525-5-63.

Thelwell RC, Weston NJV, Greenlees IA, and Hutchings NV (2008) Stressors in elite sport: A coach perspective. Journal of Sports Sciences 26: 905-918. 


\section{EXAMINING MENTAL HEALTH LITERACY IN UK COACHES}

Thelwell RC, Wagstaff CR, Rayner A, Chapman M, and Barker J (2017) Exploring athletes' perceptions of coach stress in elite sport environments. Journal of Sport Sciences 35(1): 44-55.

Thelwell RC, Wagstaff CR, Chapman MT, and Kentta G (2016) Examining coaches' perceptions of how their stress influences the coach-athlete relationship. Journal of Sport Sciences 35(19): 1928-1939.

UK Coaching (2018) Coaching in the UK, 2017: A spotlight on gender. Available online: https://www.ukcoaching.org/UKCoaching/media/coachingimages/Entity\%20base/Guides/Coaching-in-the-UK_Spotlight-on-Women_FINAL.pdf

Wei Y, Hayden J, Kutcher S, Zygmunt A, McGrath P (2013) The effectiveness of school mental health literacy programs to address knowledge, attitudes, and help-seeking among youth. Early Intervention in Psychiatry 7(2): 109-121.

White M and Casey L (2016) Helping older adults to help themselves: the role of mental health literacy in family members. Aging \& Mental Health 21: 1129-1137.

Wilson CJ, Deane FP, Ciarrochi J, and Rickwood D (2007) Measuring help-seeking intentions: properties of the general help seeking questionnaire. Canadian Journal of Counseling 39(1): 1528. 
World Health Organization (2001) Strengthening mental health promotion. Geneva: World Health Organization (Fact sheet, No. 220). 
Table 1. Demographic data

\begin{tabular}{|c|c|c|}
\hline Demographic Data & $\mathrm{M}(\mathrm{SD})$ & $\mathrm{n}(\%)$ \\
\hline Age Years & $27.87(10.58)$ & \\
\hline Gender & & \\
\hline Men & & $65(63.1 \%)$ \\
\hline Women & & $37(35.9 \%)$ \\
\hline Another gender & & $1(1.0 \%)$ \\
\hline Sexuality & & \\
\hline Heterosexual & & $85(82.5 \%)$ \\
\hline Bisexual & & $7(6.8 \%)$ \\
\hline Gay and Lesbian & & $11(10.7 \%)$ \\
\hline Ethnicity & & \\
\hline White & & $71(68.9 \%)$ \\
\hline Asian & & $10(9.7 \%)$ \\
\hline
\end{tabular}


EXAMINING MENTAL HEALTH LITERACY IN UK COACHES

\begin{tabular}{|c|c|c|}
\hline Black & & $10(9.7 \%)$ \\
\hline Arab & & $1(1.0 \%)$ \\
\hline Other & & $11(10.7 \%)$ \\
\hline Previous diagnosis of & & \\
\hline mental disorder? & & \\
\hline Yes & & $20(19.4 \%)$ \\
\hline No & & $81(78.6 \%)$ \\
\hline Prefer not to say & & $2(1.9 \%)$ \\
\hline
\end{tabular}


Table 2. Coaching data

\begin{tabular}{|c|c|}
\hline Coaching duties & \\
\hline Children & $77(74.8 \%)$ \\
\hline Adults & $25(24.3 \%)$ \\
\hline Prefer not to say & $1(1.0 \%)$ \\
\hline $\begin{array}{l}\text { Coaching Experi } \\
\text { Years }\end{array}$ & \\
\hline 1 & $17(16.5 \%)$ \\
\hline 2 & $21(20.4 \%)$ \\
\hline 3 & $19(18.4 \%)$ \\
\hline 4 or more & $46(44.7 \%)$ \\
\hline $\begin{array}{l}\text { UK Coaching } \\
\text { Certificate }\end{array}$ & \\
\hline Yes & $80(77.7 \%)$ \\
\hline No & $23(22.3 \%)$ \\
\hline
\end{tabular}


EXAMINING MENTAL HEALTH LITERACY IN UK COACHES

\begin{tabular}{|c|c|}
\hline Coaching Level & \\
\hline Beginner & $30(29.1 \%)$ \\
\hline Amateur & $66(64.1 \%)$ \\
\hline Professional/Elite & $7(6.8 \%)$ \\
\hline Sport & \\
\hline Rugby & $29(28.2 \%)$ \\
\hline Football & $16(15.5 \%)$ \\
\hline Cricket & $9(8.7 \%)$ \\
\hline Netball & $7(6.8 \%)$ \\
\hline Cheerleading/Dance & $6(5.8 \%)$ \\
\hline Swimming & $5(4.9 \%)$ \\
\hline Basketball & $4(3.9 \%)$ \\
\hline Hockey & $4(3.9 \%)$ \\
\hline
\end{tabular}


EXAMINING MENTAL HEALTH LITERACY IN UK COACHES

\begin{tabular}{|c|c|}
\hline $\begin{array}{c}\text { Racket Sports } \\
\text { (Tennis, Badminton, Squash) }\end{array}$ & $4(3.9 \%)$ \\
\hline Athletics & $4(3.9 \%)$ \\
\hline Cycling & $3(2.9 \%)$ \\
\hline Boxing & $3(2.9 \%)$ \\
\hline Gymnastics & $3(2.9 \%)$ \\
\hline Rowing & $2(1.9 \%)$ \\
\hline Running & $1(1.0 \%)$ \\
\hline Diving & $1(1.0 \%)$ \\
\hline Karate & $1(1.0 \%)$ \\
\hline Lacrosse & $1(1.0 \%)$ \\
\hline
\end{tabular}

